\title{
Comparison Between Percutaneous Kyphoplasty And Percutaneous Vertebroplasty In Terms of The Efficacy For Osteoporotic Vertebral Compression Fractures: A Meta-Analysis
}

\author{
Hai-Tao Zhu \\ Sheyang County People's Hospital \\ De-Gang Ding \\ Sheyang County People's Hospital \\ Shui Wang \\ Sheyang County People's Hospital \\ Yu-Long Zhu ( $D$ zcok35@163.com) \\ Sheyang County People's Hospital
}

Research

Keywords: Percutaneous kyphoplasty, Percutaneous vertebroplasty, Osteoporotic vertebral compression fracture, Meta-analysis

Posted Date: June 30th, 2021

DOl: https://doi.org/10.21203/rs.3.rs-609136/v1

License: (c) (i) This work is licensed under a Creative Commons Attribution 4.0 International License.

Read Full License 


\section{Abstract}

Background \& Aim: Osteoporotic vertebral compression fractures (OVCFs) are acknowledged as common occurred fractures among humans, especially for the elderly population. The minimally invasive percutaneous methods such as kyphoplasty as well as vertebroplasty have been valid and effective tools in terms of reducing clinical problems, which are associated with more beneficial effects as compared to traditional methods such as open surgery or conservative treatment. Hence, we conducted the current meta-analysis in order to gather updated evidence available for the systematical assessment of the clinical and radiographic outcomes of VP in comparison of KP.

Methods: Publications on comparison kyphoplasty versus vertebroplasty in treatment of OVCFs were collected. After rigorous and thorough review of quality, we extracted the data on the basis of eligible trials, which analyzed the summary hazard ratios (HRs) of the endpoints of interested.

Results: Totally, our inclusion criteria involved five studies. 561 subjects involving 334 patients received VP and 227 patients received KP were included, of which patients receiving KP or VP failed to show any significant differences in the visual analog scale (VAS) scores (MD $=-0.02,95 \% \mathrm{Cl}-0.40-0.35 ; \mathrm{P}=$ $0.91)$, and the risk of cement leakage $(\mathrm{OR}=1.60,95 \% \mathrm{Cl} 0.82-3.12 ; \mathrm{P}=0.17)$. Nevertheless, the Oswestry Disability Index (ODI) scores (MD =-1.56, 95\% Cl-2.39 - -0.73; $\mathrm{P}=0.0002)$, the injected cement volume $(\mathrm{MD}=-0.40,95 \% \mathrm{Cl}-0.77--0.04 ; \mathrm{P}=0.03)$ and the operation time $(\mathrm{MD}=-9.67,95 \% \mathrm{Cl}-11.55--7.80 ; \mathrm{P} \triangle$ 0.00001) in VP group were linked to markedly lower trend in comparison of KP group with significant statistical difference.

Conclusion: The present meta-analysis controls the acceptable level of the efficacy across the involved trials. The VP had ODI scores, the injected cement volume and the operation time exerted several advantages in this meta-analysis. Yet, VP failed to show benefits in terms of the VAS scores and cement leakage in comparison of KP therapy. Given the combined results of our study, the optimal treatment for patient harboring OVCFs should be determined by further high-quality and multi-center RCTs along with longer follow-ups as well as larger sample size.

\section{Introduction}

Osteoporotic vertebral compression fractures (OVCFs) have been regarded as one of the most widely occurred complications of osteoporosis in elderly patients, which are often accompanied with severe back pain and restrict activity, affecting patients' life quality with increased mortality ${ }^{1-3}$. The OVCFs, which are generally occurred due to osteoporosis, have been currently considered a major health issue among wide range of population around the globe. It has been acknowledged that most of OVCFs can be alleviated even cured within a few months though conservative therapy.

Only one-third patients show symptoms, thus proper conservative therapies are often given to general patients, involving analgesics, bed rest, and external bracing ${ }^{4}$. While, the conservative treatments may 
cause complications such as pulmonary infection, pulmonary embolism and venous thrombosis, seriously affect the life quality of patients, even result in death ${ }^{5,6}$.

In case of failure of the above mentioned non-surgical approaches, surgical therapy has initially been applied as the main treatment for the disease. However, there are chances that traditional open surgery with metal implants fails and leads to neurological symptoms, persistent back pain and limited functions due to the poor quality of the osteoporotic bone 7,8 . Therapy should seek earlier surgical intervention, such as KP and VP.

Kyphoplasty and vertebroplasty are two minimally invasive operative procedures available as effective tools in terms of treating symptomatic OVCFs ${ }^{9-11}$. In spite of the beneficial effect of both procedures in relieving the back pain as well as improving the life quality ${ }^{11-13}$, debates exist concerning the superior therapeutic effect between these two approaches. Some studies have demonstrated that KP can better restore the compressed vertebral body height as well as correct kyphosis of the spine.While, no significant difference was observed in VAS scores and ODI scores between the two groups. Here, the present metaanalysis was conducted for the comparison of the radiographic and clinical difference of KP and VP in OVCFs patients.

\section{Methods And Materials}

Ethical approval

Ethical approval was waived because this study does not involve any human participants or animals.

Retrieval strategy

The following electronic databased were identified and searched by two studiers separately: Embase, PubMed, Cochrane library in latest 5 years updated to December 2020. The data searching process was conducted in search of all publications with the keywords: "percutaneous kyphoplasty" AND "osteoporotic vertebral compression fracture", AND "percutaneous vertebroplasty". We also screened and checked relevant Medical Subject Heading (MeSH) terms. no limitation was used during the process of literature search. In addition, we hand-searched the references of eligible publications that dealt with the topic of interest with an attempt to search associated studies.

\section{Eligibility criteria}

Studies that met the following criteria should be involved in current the meta-analysis: (1) the studies were designed to compare VP with KP therapy; (2) articles involving OVCFs patients; (3) the end-point of interests were provided, including the visual analog scale (VAS) scores, Oswestry Disability Index (ODI) scores, the injected cement volume, the operation time and cement leakage rate. The studies that failed to meet the predefined inclusion criteria should be excluded from the present meta-analysis. 
The retrieved studies were evaluated independently by two investigators. On the basis of The Cochrane Handbook for Systematic Reviews of Interventions, we utilized the risk of bias items (ROBI).

Data extraction

Two reviewers conducted and evaluated the data extraction separately. Any arising differences were settled through discussion to reach general consensus. The main categories from selected studies were based on the following items: year of publication, family name of first author, study design, median age, and main outcomes. The risk ratios (RRs) and corresponding hazard ratios (HRs) were extracted to further describe the outcomes of interest data, respectively, with its $95 \%$ confidence intervals (Cls).

Statistics analysis

We also conducted a sensitivity analysis for the assessment of the impact on the aggregated results through the heterogeneity in the included studies. Heterogeneity of the trial results was assessed with the $I^{2}$ statistic to select ideal analysis model ${ }^{14}$, describing as followed respectively: low, $25-50 \%$; moderate, $50-75 \%$; or high, $>75 \%^{15}$. We calculated summary outcome through the use of fixed-effect models when low heterogeneity showed among studies. Otherwise, we utilized the random-effect models. We applied Review Manager version 5.3 software (Revman; The Cochrane collaboration Oxford, United Kingdom) to conduct the statistical analyses. Studies with a P value less than 0.05 was thought to have statistical significance. Forest plots showed the findings of our meta-analysis.

\section{Results}

\section{Literature search process and study characteristics}

Totally, 353 publications were identified originally for study assessment. On basis of above mentioned criteria, there were a total of 11 publications in search of further details. Finally, 5 studies(16-20)were included in the present analysis due to some failed to offer sufficient outcome data of two approaches. In all, 561 subjects involving 334patients received VP and 227 patients received KP were included, Fig. 1 described the detailed search process.

The above mentioned studies were on the bases of the evidence with moderate to high quality. Table 1 described the major characteristics of the qualified studies in more detail.

Table 1 Basic characteristic of included studies. 


\begin{tabular}{|c|c|c|c|c|c|c|}
\hline \multirow[t]{2}{*}{$\begin{array}{l}\text { Author } \\
\text { Year }\end{array}$} & \multirow[t]{2}{*}{ Study design } & \multicolumn{2}{|c|}{$\begin{array}{l}\text { No. of } \\
\text { patients }\end{array}$} & \multicolumn{2}{|c|}{ Median age } & \multirow[t]{2}{*}{ The interested results } \\
\hline & & VP & $\mathrm{KP}$ & VP & $\mathrm{KP}$ & \\
\hline $\begin{array}{l}\text { Zhang } \\
\text { G } \\
2015\end{array}$ & $\begin{array}{l}\text { Retrospective } \\
\text { cohort study }\end{array}$ & 38 & 35 & 75.58 & 73.74 & $\begin{array}{l}\text { VAS scores, the injected cement volume, } \\
\text { cement leakage rate, the operation time }\end{array}$ \\
\hline $\begin{array}{l}\text { Zhang } \\
\text { J } \\
2018\end{array}$ & $\begin{array}{l}\text { Retrospective } \\
\text { cohort study }\end{array}$ & 22 & 13 & 72.82 & 74.38 & $\begin{array}{l}\text { VAS scores, ODI scores, the injected } \\
\text { cement volume, cement leakage rate }\end{array}$ \\
\hline $\begin{array}{l}\text { Wang } \\
\text { F } \\
2018\end{array}$ & $\begin{array}{l}\text { Retrospective } \\
\text { study }\end{array}$ & 31 & 26 & 74.8 & 75.3 & $\begin{array}{l}\text { VAS scores, ODI scores } \ \text { the injected } \\
\text { cement volume, cement leakage rate, the } \\
\text { operation time }\end{array}$ \\
\hline $\begin{array}{l}\text { Cheng } \\
\text { J } \\
2019\end{array}$ & $\begin{array}{l}\text { Retrospective } \\
\text { cohort study }\end{array}$ & 215 & 125 & 66.7 & 68.4 & $\begin{array}{l}\text { VAS scores, ODI scores, the injected } \\
\text { cement volume }\end{array}$ \\
\hline $\begin{array}{l}\text { Chang } \\
\text { J } \\
2020\end{array}$ & $\begin{array}{l}\text { Randomized } \\
\text { controlled trial }\end{array}$ & 28 & 28 & 75 & 75.1 & $\begin{array}{l}\text { VAS scores, ODI scores, the injected } \\
\text { cement volume, cement leakage rate, the } \\
\text { operation time }\end{array}$ \\
\hline
\end{tabular}

\section{Clinical and methodological heterogeneity}

Pooled analysis of Oswestry Disability Index (ODI) scores comparing KP and VP groups

Pooling the data of the ODI scores retrieved from seven studies showed significant differences in the patients with regard to the tendency of receiving VP in comparison of the KP group (MD $=-1.56,95 \% \mathrm{Cl}$ $-2.39--0.73 ; P=0.0002$ )(Fig. 2).

Pooled analysis of the visual analog scale (VAS) scores comparing KP and VP groups

In order to pool the VAS scores data, random- effects model was applied due to the moderate heterogeneity across five studies. The pooled data did not show advantage in the KP or VP groups(MD $=-0.02,95 \% \mathrm{Cl}-0.40-0.35 ; \mathrm{P}=0.91$ ) (Fig. 3).

Pooled analysis of the injected cement volume comparing KP and VP groups

For the KP and VP groups, there is a significant differences in terms of comparing VP and KP groups were observed (MD =-0.40, 95\% Cl-0.77- -0.04; $\mathrm{P}=0.03$ ) (Fig. 4).

Pooled analysis of the operation time comparing KP and VP groups

The operation time was available for 3 trials. Results showed that the operation time (MD $=-9.67,95 \% \mathrm{Cl}$ $-11.55--7.80 ; \mathrm{P}<0.00001$ ) in VP group were linked to markedly lower trend in comparison of KP group with significant statistical difference (Fig. 5). 
Pooled analysis of cement leakage rate comparing VP and KP groups

The cement leakage rate was reported in 4 studies. While, the pool data does not reach a statistically significant level $(\mathrm{OR}=1.60,95 \% \mathrm{Cl} 0.82-3.12 ; \mathrm{P}=0.17)($ Fig. 6).

\section{Discussion}

Vertebroplasty and kyphoplasty are acknowledged as percutaneous minimally invasive procedures, which could quickly alleviate long-lasting postoperative pain and proven to be alternative approaches apart from the hitherto existing therapies(21-22). According to the study supported and published by

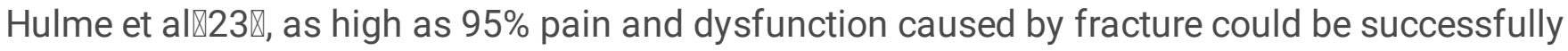
alleviated through vertebroplasty and kyphoplasty. McLiernan et al.囚24囚performed a study that found beneficial effects on life quality among patients receiving vertebroplasty in the course of 12 months. In addition, according to a prospective study published by Liebermann et al. ${ }^{6}$, remarkable improvement was found in the SF-36 score for kyphoplasty. Nonetheless, studies available to evaluate KP and VP in OVCFs are limited due to the small-scale studies and case reports. Currently, debates exist regarding the better efficacy of VP and KP in the therapy of OVCFs.

In the current analysis, the interested results contained two major categories, the clinical outcome and the radiographic outcome The radiographic outcome involved the following parameters: the injected cement volume, and cement leakage. Vertebroplasty requires cement to perform the image-guided percutaneous injection into a fractured vertebra in order to stabilize the fracture as well as alleviate pain. There are several superior effect of kyphoplasty as compared with vertebroplasty, such as the percutaneous expansion of an inflation bone tamp to correct kyphosis secondary to collapsed vertebral bodies(25). While, in terms of the risk of cement leakage, there was no significant statistical difference between the two groups in our study. These above mentioned findings may be contradicting with what the previous literature reported $₫ 23,25 \rrbracket$.

As compared to our pooled results, KP was associated with significantly longer operation time versus the VP, which is consistent with the latest meta-analysis by Hongyu Wei(26). One possible explanation is the need of more complex procedures with KP, such as the repeated establishment of expander channel on the pedicle.

In addition, bone cement leakage is considered as the most common complication of bone cement vertebroplasty. To our knowledge, the higher rate of cement leakage is related to the high injection pressure with low viscosity of the cement during VP in comparison of KP. In contrast, the KP procedure can offer a cavity for cement to be injected into the center with the help of inflated balloon tamp. Lower rate of cement leakage is highly associated with the methodological difference of KP. While, it is possible that balloon distraction during the process of KP might not only result in the damage of vertebral wall and upper and lower endplates, but also increase the risk of cement leakage due to the poor vertebral 
strength of OVCFs patients(18). Thus, we demonstrated that there was no difference between patients receiving KP or VP in terms of the cement leakage.

The clinical outcomes included ODI scores as well as VAS scores. Most studies have demonstrated a continuous and statistically significant reduction of ODI and VAS scores on the basis of the two study groups, suggesting the beneficial effect of VP and KP in reducing the symptoms of back pain as well as improving life quality.Our study reported that the ODI scores were remarkably altered in the kyphoplasty group. As for the VAS scores, KP failed to show benefits.

In this systematic analysis, we assessed the radiographic and clinical difference of KP compared with VP for OVCFs patients. Admittedly, our study had several limitations. On the one hand, the limitations can be inherent to the included RCT and retrospective study, which may result in the imbalance between the two study groups. Bias exist, and this may influence the outcomes. We recognized the need for additional random clinical trials and studies. On the other hand, considering the lack of patient-level data and the present study-level meta-analysis, the clinical heterogeneity among trials should not be ignored for the further interpretation of our current findings.

\section{Conclusion}

The current evidence has contributed to understanding that vertebroplasty can statistically alter the ODI scores, the injected cement volume and the operation time in comparison of kyphoplasty. While, the VAS scores and the risk of cement leakage failed to show significant influence among the two groups. Given the above mentioned limitations of our meta-analysis, it is crucial to continue investigating the effect of KP and VP with high-quality RCTs based on larger multicenter and longer follow-up studies to confirm the current findings.

\section{Abbreviations}

Osteoporotic vertebral compression fractures (OVCFs); hazard ratios (HRs); Oswestry Disability Index (ODI); visual analog scale (VAS)

\section{Declarations}

Ethics approval and consent to participate: Ethical approval was waived because this study does not involve any human participants or animals. Consent to participate was not applicable.

Consent for publication: Not applicable.

Availability of data and materials: The datasets generated and analyzed during the current study are available from the corresponding author on reasonable request.

Competing interests: The authors declare there is no conflict of interest. 
Funding: No funding was received for this study.

Authors' contributions: All authors have made substantial contributions to conception and design of the study, searching literature, extracting data and analyzing data. Hai-Tao Zhu wrote the manuscript; YuLong Zhu revised the manuscript; All authors approved the final version of the manuscript.

Acknowledgements: None.

\section{References}

1. Landham PR, Baker-Rand HL, Gilbert SJ, et al. Is kyphoplasty better than vertebroplasty at restoring form and function after severe vertebral wedge fractures? The spine journal : official journal of the North American Spine Society. Apr 1 2015;15(4):721-732.

2. Edidin AA, Ong KL, Lau E, Kurtz SM. Morbidity and Mortality After Vertebral Fractures: Comparison of Vertebral Augmentation and Nonoperative Management in the Medicare Population. Spine. Aug 1 2015;40(15):1228-1241.

3. Kado DM, Browner WS, Palermo L, Nevitt MC, Genant HK, Cummings SR. Vertebral fractures and mortality in older women: a prospective study. Study of Osteoporotic Fractures Research Group. Archives of internal medicine. Jun 14 1999;159(11):1215-1220.

4. Cooper C, Atkinson EJ, O'Fallon WM, Melton LJ, 3rd. Incidence of clinically diagnosed vertebral fractures: a population-based study in Rochester, Minnesota, 1985-1989. Journal of bone and mineral research : the official journal of the American Society for Bone and Mineral Research. Feb 1992;7(2):221227.

5. Hide IG, Gangi A. Percutaneous vertebroplasty: history, technique and current perspectives. Clinical radiology. Jun 2004;59(6):461-467.

6. Lieberman IH, Dudeney S, Reinhardt MK, Bell G. Initial outcome and efficacy of "kyphoplasty" in the treatment of painful osteoporotic vertebral compression fractures. Spine. Jul 15 2001;26(14):1631-1638.

7. Phillips FM, Pfeifer BA, Lieberman IH, Kerr EJ, 3rd, Choi IS, Pazianos AG. Minimally invasive treatments of osteoporotic vertebral compression fractures: vertebroplasty and kyphoplasty. Instructional course lectures. 2003;52:559-567.

8. Garfin SR, Yuan HA, Reiley MA. New technologies in spine: kyphoplasty and vertebroplasty for the treatment of painful osteoporotic compression fractures. Spine. Jul 15 2001;26(14):1511-1515.

9. Rousing R, Andersen MO, Jespersen SM, Thomsen K, Lauritsen J. Percutaneous vertebroplasty compared to conservative treatment in patients with painful acute or subacute osteoporotic vertebral fractures: three-months follow-up in a clinical randomized study. Spine. Jun 1 2009;34(13):1349-1354. 
10. Rousing R, Hansen KL, Andersen MO, Jespersen SM, Thomsen K, Lauritsen JM. Twelve-months follow-up in forty-nine patients with acute/semiacute osteoporotic vertebral fractures treated conservatively or with percutaneous vertebroplasty: a clinical randomized study. Spine. Mar 1 2010;35(5):478-482.

11. Wardlaw D, Cummings SR, Van Meirhaeghe J, et al. Efficacy and safety of balloon kyphoplasty compared with non-surgical care for vertebral compression fracture (FREE): a randomised controlled trial. Lancet. Mar 21 2009;373(9668):1016-1024.

12. Papanastassiou ID, Phillips FM, Van Meirhaeghe J, et al. Comparing effects of kyphoplasty, vertebroplasty, and non-surgical management in a systematic review of randomized and non-randomized controlled studies. European spine journal : official publication of the European Spine Society, the European Spinal Deformity Society, and the European Section of the Cervical Spine Research Society. Sep 2012;21(9):1826-1843.

13. Folman Y, Shabat S. A comparison of two new technologies for percutaneous vertebral augmentation: confidence vertebroplasty vs. sky kyphoplasty. The Israel Medical Association journal : IMAJ. Jul 2011;13(7):394-397.

14. Higgins JP, Thompson SG. Quantifying heterogeneity in a meta-analysis. Statistics in medicine. Jun 15 2002;21(11):1539-1558.

15. Higgins JP, Thompson SG, Deeks JJ, Altman DG. Measuring inconsistency in meta-analyses. Bmj. Sep 6 2003;327(7414):557-560.

16. Zhang G Q , Gao Y Z , Chen S L, et al. Comparison of percutaneous vertebroplasty and percutaneous kyphoplasty for the management of Kümmell's disease: A retrospective study[J]. Indian Journal of Orthopaedics, 2015.

17. Zhang J N , Fan Y, He X, et al. Is percutaneous kyphoplasty the better choice for minimally invasive treatment of neurologically intact osteoporotic Kümmell's disease? A comparison of two minimally invasive procedures[J]. International Orthopaedics, 2018.

18. Wang F, Wang L F , Miao D C , et al. Which one is more effective for the treatment of very severe osteoporotic vertebral compression fractures: PVP or PKP?[J]. Journal of Pain Research, 2018, Volume $11: 2625-2631$.

19. Junjie, Cheng, Aikeremujiang, et al. Percutaneous vertebroplasty vs balloon kyphoplasty in the treatment of newly onset osteoporotic vertebral compression fractures: A retrospective cohort study.[J]. Medicine, 2019.

20. Chang J, Bei M, Shu D, et al. Comparison of the clinical outcomes of percutaneous vertebroplasty vs. kyphoplasty for the treatment 
of osteoporotic Kümmell's disease: a prospective cohort study. BMC 48. Musculoskelet Disord. 2020;21(1):238.

21囚Perez-Higueras A, Alvarez L, Rossi RE, Quinones D, Al-Assir I. Percutaneous vertebroplasty: long-term clinical and radiological outcome. Neuroradiology. Nov 2002;44(11):950-954.

22.Voggenreiter G, Lenz E, Obertacke U. Effectiveness of Vertebroplasty and kyphoplasty in height restoration of osteoporotic vertebral compression fractures. Akt Traumatol. 2006;36:1-5.

23. Hulme PA, Krebs J, Ferguson SJ, Berlemann U. Vertebroplasty and kyphoplasty: a systematic review of 69 clinical studies. Spine. Aug 1 2006;31(17):1983-2001.

24. McKiernan F, Faciszewski T, Jensen R. Does vertebral height restoration achieved at vertebroplasty matter? Journal of vascular and interventional radiology : JVIR. Jul 2005;16(7):973-979.

25. Hu KZ, Chen SC, Xu L. Comparison of percutaneous balloon dilation kyphoplasty and percutaneous vertebroplasty in treatment for thoracolumbar vertebral compression fractures. European review for medical and pharmacological sciences. Jul 2018;22(1 Suppl):96-102.

26هWei H, Dong C , Zhu Y, et al. Analysis of two minimally invasive procedures for osteoporotic vertebral compression fractures with intravertebral cleft: a systematic review and meta-analysis[J]. Journal of Orthopaedic Surgery and Research, 2020, 15(1):401.

\section{Figures}




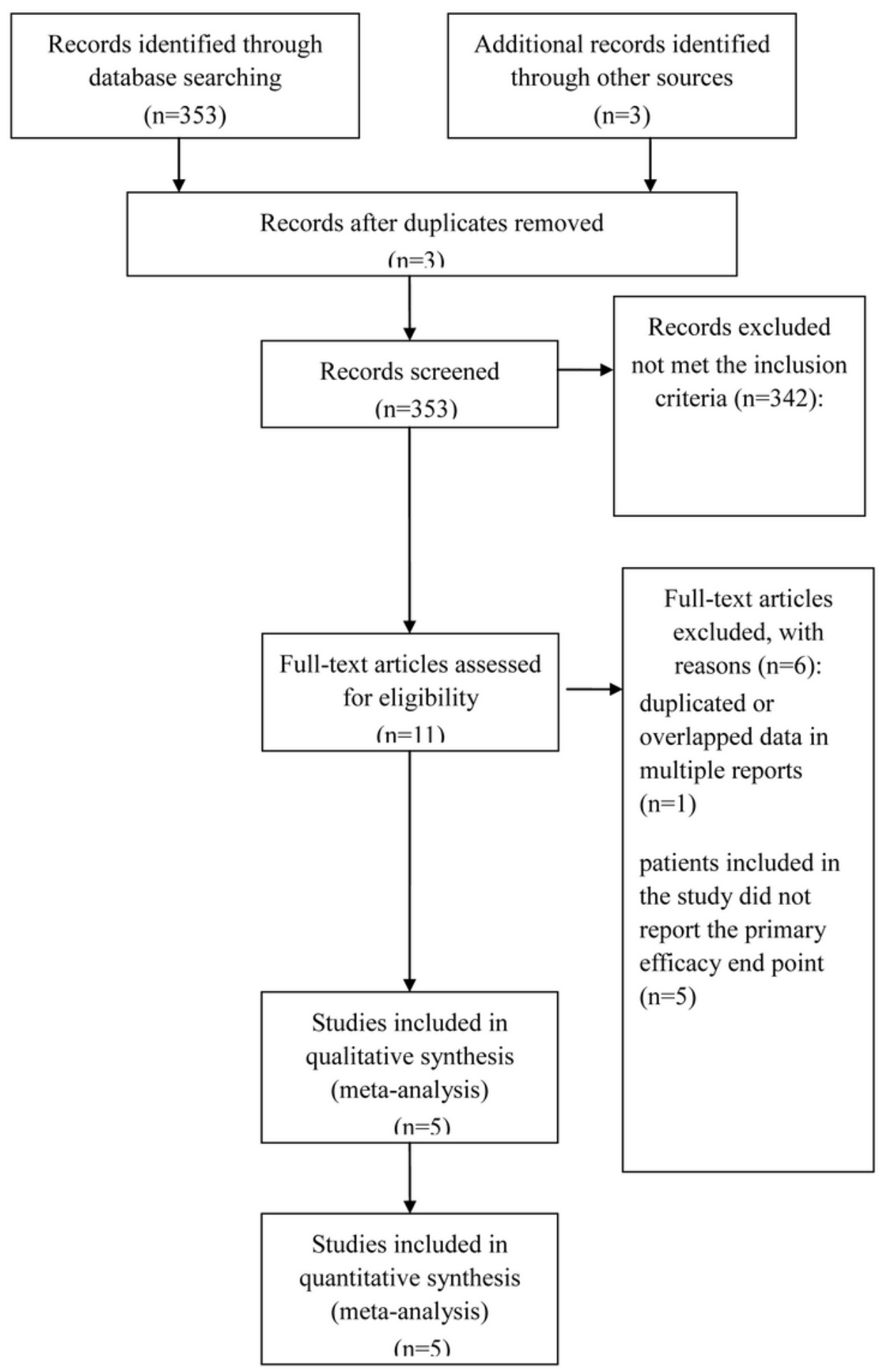

\section{Figure 1}

PRISMA flow chart of selection process to identify eligible studies 


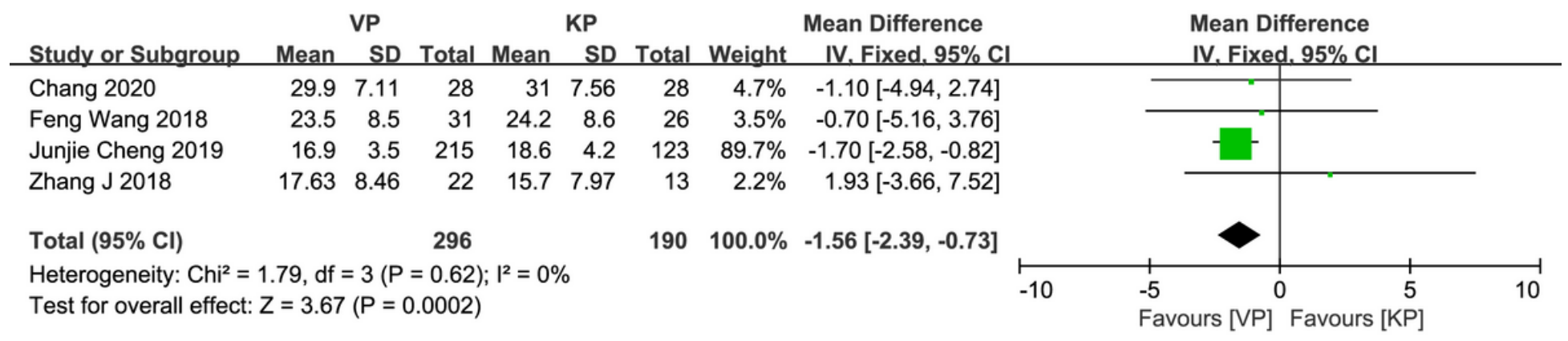

Figure 2

Pooled analysis of Oswestry Disability Index (ODI) scores

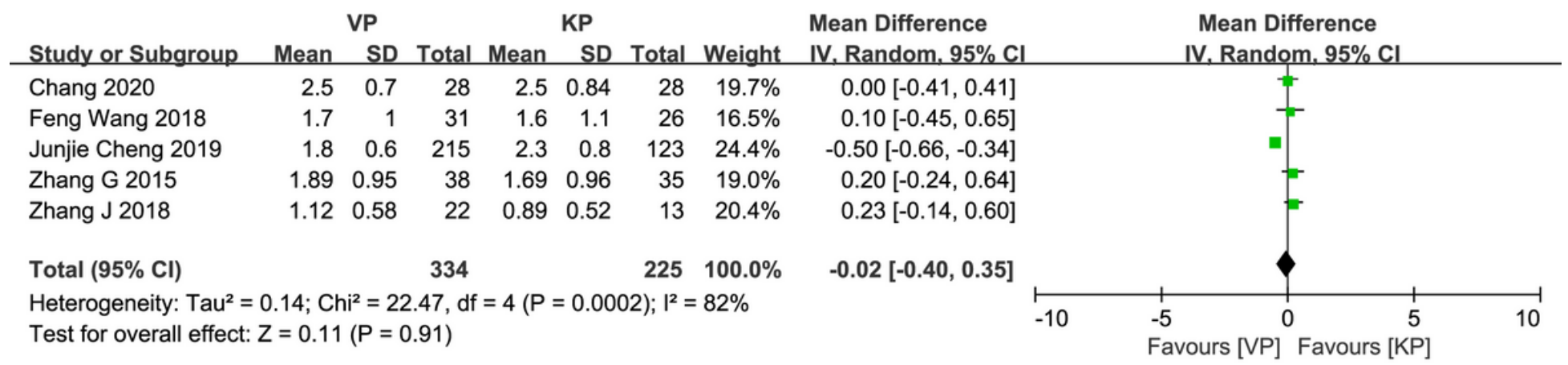

\section{Figure 3}

Pooled analysis of the visual analog scale (VAS) scores

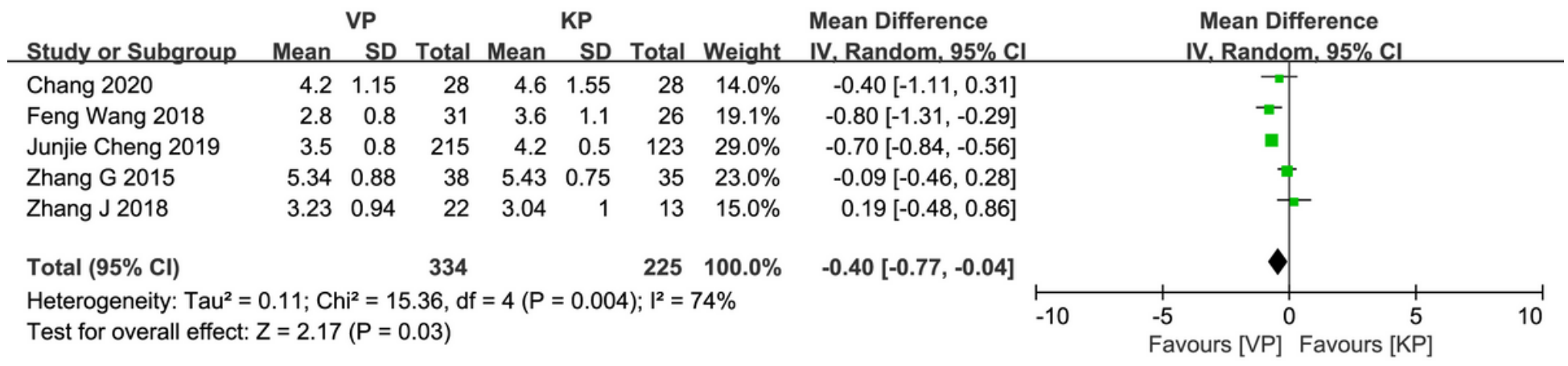

\section{Figure 4}

Pooled analysis of injected cement volume

\begin{tabular}{|c|c|c|c|c|c|c|c|c|c|c|c|c|}
\hline Study or Subgroup & \multicolumn{3}{|c|}{ VP } & \multicolumn{3}{|c|}{ KP } & Weight & $\begin{array}{l}\text { Mean Difference } \\
\text { IV. Random, } 95 \% \mathrm{Cl}\end{array}$ & \multicolumn{4}{|c|}{$\begin{array}{c}\text { Mean Difference } \\
\text { IV, Random, } 95 \% \mathrm{Cl}\end{array}$} \\
\hline Chang 2020 & 34.8 & 3.47 & 28 & 45.1 & 5.15 & 28 & $29.2 \%$ & $-10.30[-12.60,-8.00]$ & & 口 & & \\
\hline Feng Wang 2018 & 29.6 & 3.3 & 31 & 37.4 & 4.2 & 26 & $32.8 \%$ & $-7.80[-9.79,-5.81]$ & & - & & \\
\hline Zhang G 2015 & 34.68 & 2.42 & 38 & 45.49 & 4.12 & 35 & $38.1 \%$ & $-10.81[-12.38,-9.24]$ & & - & & \\
\hline Total $(95 \% \mathrm{Cl})$ & & & 97 & & & 89 & $100.0 \%$ & $-9.67[-11.55,-7.80]$ & & $\downarrow$ & & \\
\hline $\begin{array}{l}\text { Heterogeneity: } \mathrm{Tau}^{2}= \\
\text { Test for overall effect }\end{array}$ & $\begin{array}{l}1.78 ; C \\
Z=10 . C\end{array}$ & $\begin{array}{l}\mathrm{i}^{2}=5 . \\
9(\mathrm{P}<\end{array}$ & $\begin{array}{l}66, \mathrm{df}= \\
0.0000\end{array}$ & $2(P=$ & $0.06)$ & $\left.\right|^{2}=65$ & & & -100 & $\begin{array}{l}-50 \\
\text { Favours [VP] }\end{array}$ & $\begin{array}{lr}0 & 50 \\
\text { Favours } & {[\mathrm{KP}]}\end{array}$ & 100 \\
\hline
\end{tabular}


Figure 5

Pooled analysis of the operation time

Figure 6

Pooled analysis of cement leakage rate 